\title{
AC 2009-2020: NETWORK PARTICLE TRACKING (NPT) FOR ECOSYSTEM THERMODYNAMICS AND RISK ANALYSIS
}

\section{Ernest Tollner, University of Georgia, Athens}

\section{John Schramski, University of Georgia}

Building on a distinguished and a uniquely diverse career in both public and private industry Dr.

Schramski is a member of both the Environmental Engineering Faculty and the Systems \& Engineering Ecology Research Program at the University of Georgia. Among other areas, his research and pedagogical pursuits include ecosystem energetics, industrial ecology, ecological network analysis, and engineering education curriculum. Currently, his engineering education research includes his restructuring of the traditional thermodynamic and heat transfer engineering courses into a novel three-course sequence conceived and ultimately oriented by the premise that the existence of readily usable energy is solely a function of the biosphere's distance from thermodynamic equilibrium. This thermodynamic second law perspective is fundamentally changing Environmental Engineering curriculum and the ecosystem-derived perspective of the students graduating from this program.

\section{Caner Kazanci, University of Georgia}

Dr. Caner Kazanci is a native of Izmir, Turkey and received his MS and PhD degrees in Mathematical Sciences Department from Carnegie Mellon University, Pittsburgh, PA. His graduate work was on mathematical biology, and was concerned with modeling and analysis of large biochemical pathways. He is currently an assistant professor at the University of Georgia, in a joint appointment in Department of Mathematics and Faculty of Engineering. He is the developer of EcoNet, a web based software for ecosystem modeling, simulation and analysis. Dr. Kazanci and Dr. Tollner developed Network Particle Tracking (NPT), a new agent-based simulation technique that provides detailed analysis of ecological networks, which is compatible with the conventional differential equation representation of ecosystem models. 


\title{
Network Particle Tracking (NPT) for Ecosystem Thermodynamics and Risk Analysis
}

\begin{abstract}
Network Particle tracking (NPT), building on the network environ analysis (NEA) foundation, represents a new development in the soft realist epistemological trajectory defined by numerous studies that have defined existential subsystems and coherence relations among the systems. Three ecosystem models are evaluated using conventional NEA approaches and with NPT. Compartments in a model with high indirect effects and Finn's cycling index showed a lack of correlation among compartments between NEA storage/throughflow versus particle repeat visits numbers/particles in compartments at steady state, while with two models having lower indirect effect/Finn's cycling, the correlation between NEA and NPT outputs was high. In an analysis of ecological orientors associated with NEA, it became apparent that NPT fully supports the conventional NEA analysis when the common assumptions of donor control and steady state flows are satisfied. Being able to track particle history enables views of multiple scales and the possibility of making pathway-dependent modeling decisions. NPT enables researchers and students alike to have a more realistic view of compartment dynamics in ecological and, by extension, other similar compartmental models found in bioprocessing and environmental domains.
\end{abstract}

Key Words: stochastic differential equation, network environ analysis, input-output models, compartment modeling, network particle tracking, ecological network.

\section{Background}

Definitions of an ecosystem that form distinct subsections of the biosphere are a common feature of many ecosystem models (Barkmann et al. 1998). These authors acknowledge delineated ecosystems have a subjective quality but never-the-less exist as units, which in principle may be described empirically as open systems. These systems exhibit developmental trends abstracted from observational data (e.g., Fath et. al 2004). Following classical enlightenment era approaches, Newtonian determinism prevailed in ecological modeling efforts beginning with linear trophic models, thoroughly western and Newtonian in orientation (e.g., Matis et. al 1979).

Patten and colleagues developed network environ analysis (NEA) (Patten 1978, Barber et al. 1979, Fath and Patten 1999, Fath and Borrett 2006, Schramski 2006), a form of Ecological Network Analysis (ENA), to model the networks of complex ecological systems. Affording particular mathematical and ecological interpretive advantages, NEA uniquely represents objects as simultaneously participating in the dual environments of both their incoming and outgoing networks. ENA and NEA in 
particular reflect the organic holism of ecological systems and are built upon a deterministic premise. Recently, various thermodynamic goal functions have been proposed with NEA and other modeling approaches to describe developmental trends of ecosystems (Jørgensen and Nielsen 1998, Fath et. al 2001, Jørgensen and Fath 2004).

Motivated by considerations from information theory and statistical thermodynamics , Tollner and Kazanci (2007) presented a network modeling algorithm known as "Network Particle Tracking (NPT)" which is an extension of NEA. NPT models ecological systems by maintaining the system perspective yet providing a method for visualizing real time change within compartments. NPT is based on a discretization of mass or energy flows and storages in ecological networks into a series of 'particles' or 'quanta' of an identified mass or energy constituent (we will use 'particle' from this point forward). Using a compartment network model as depicted in Figure 1, each particle is followed from input through the system to output. An improved version of Gillespie's algorithm (1977) for solving stochastic differential equations greatly extended the tracking capability of the Tollner and Kazanci (2007) approach enabling feasible solutions to ecological-scale problems. Knowing particle routing probabilities provides interpretive insight as to how particular 'particles' of energy or mass may move through a system before exiting. Kazanci and Tollner (2008) mark and follow each discrete element, with the unique capability of attaching various identifying attributes to each particle as it routes through compartments maintaining a historical record of compartment contacts. NPT is essentially an individual based (or agent based) method which deduces its rules on how an individual particle will move directly from the differential equation representation of the network model. This eliminates the need for extra parameters or decisions required to build an individual based model. Therefore causality is preserved. NPT is a stochastic method that is compatible with the so called "master equation" (Gillespie 1977, 1992, 2000). In other words, the mean of many NPT simulations agrees with the differential equation solution. This property enables accurate comparison of NPT results with conventional simulation and analysis.

Each particle's identity and routing history, similar to international travelers' passport data (see Figure 1), can be further augmented with additional information documenting all desired aspects or properties of travel through the network. The travel history could also be used to gather additional routing information or as insight for other decisions. For example, chemical energy changes may be logged to calculate exergy content variations, or steady-state models can be inspected to determine a distribution of system and compartment residence times. NPT weaves a stochastic nominalism into the organic holism and Newtonian determinism of ecological network modeling. Patten (1998) articulated a series of orientor statements to describe the basic 
principles which define the tendencies of directional development, self organization and auto evolution. NPT provides an approach for mimicking and modeling some of the principles.

The objective of this presentation is to elucidate what NPT is in an ecological context and to present some anecdotal experience with how NPT can help researchers and students to better visualize what happens when materials flow through ecological compartment models in specific and other compartmental reactor models common in bioprocessing in general.

\section{Network Particle Tracking Analysis and Network Environ Analysis}

We study three different ecosystem models using NEA and NPT. First, we use NPT to study how particles are "distributed in the system" or "shared by compartments within the network". To quantify this property, we focus on particles that are stored within a compartment at a given time. As illustrated in Figure 1, NPT provides the pathway history of each particle; therefore we know how many other compartments a particle has been to previously. Note that this value can be very high, depending on how much cycling occurs in the network. For each compartment in the network, we create a histogram of these values based on all particles residing in that compartment (See Figures $3 a, b$ and $c)$. For example, the value $(x, y)=(12,71)$ on the histogram for Detritus compartment represents the fact that there are 71 particles residing in Detritus compartment that has previously stopped by other compartments 12 times. This number 12 includes repeated compartments, including Detritus. One concern here is that NPT is a dynamic simulation; therefore this histogram will evolve in time. However, given enough simulation time, it converges to a steady state distribution, which is what we focus on in this paper.

Using EcoNet (Kazanci 2007) and the subsequent statistical histograms of a particle's compartment visits we focused on the Finn Cycling Index (FCI) (Finn 1976), dominance of indirect effects (Higashi and Patten 1989), and storage and throughflow analysis in our NEA versus NPT comparisons. The EcoNet-produced digraphs of three models ( 2 mass-based and 1 energy) selected to provide variations in NEA outputs are shown in Figures 2a, b, and c. Tables 1a, b, and c provide selected NEA and NPT results. FCIs range from 0.12 to 0.97 and the Indirect to Direct Effects ratios range from 0.61 to 211 . The low cycling in the marine model (Table 1c) hampered the accumulation of particle statistics. Histograms of contact visits versus frequency generated by NPT for one compartment of the Tropical Forest system of Webster et al (1970) are given in Figure 3. Of the several statistical distributions investigated with each modelcompartment combination, the cumulative exponential distribution consistently best described the number of compartments visited by a typical particle, particularly over the lower number of visits. The log-normal distribution was the best fit at high compartment visit frequencies in several cases. These observations held consistently 
for the near steady-state condition over the models and compartments investigated in this study.

Table 1 shows the NEA compartment storage and throughflow data for each of the three models. The mean particle number for a given compartment was the average numbers of compartments visited by the particles in the respective compartments since startup. The NEA storage was computed by a column sum of the NEA storage matrix, reflecting that the source could have been any other connected compartment.

NEA storage (Figures $4 a$ and 5a) and throughflow (Figures $4 b$ and 5b) for all three models were plotted versus the average number of contacts (Fig 4a, 5a) and the steadystate storage value vs. average contacts by particles in that compartment (Fig. 4b, 5b) and the NEA mean storage or throughflow based on the storage or throughflow matrix. The Webster model (with the highest FCI $=0.97$ and Indirect to Direct Effects ratio $=211$ of the three models evaluated) show considerable variation in particle contents and compartment residence data versus both NEA storage (Figures $4 a$ and 5a) and throughflow (Figures $4 \mathrm{~b}$ and $5 \mathrm{~b}$ ) values whereas other models were more homogenous across compartments. As FCI and the Indirect to Direct effect ratios increase the correlation between NEA statistics and NPT outputs may diverge. Network homogenization would logically increase with high FCI values. NPT for these systems enables a more in-depth analyses of model compartments particularly when the tracking attributes of compartments are substantially different (e.g., reserves versus consumers).

In general, there are many kinds of mathematical analyses originally developed and used for engineering purposes that are now available for application to the growing set of complex systems problems represented by human interactions with environment. Potential benefits from such knowledge may extend to risk assessment applications or to knowing where collections of specific compounds may most likely concentrate to cause new network connections or emergence of new states. For example, NPT may enable following a contaminant particle through a system wherein it could be tagged with accumulative indices based on compartmental visits and residence times. A critical value of these indices could trigger an adverse or beneficial symptom leading to a system change. The original goal of using NPT for further developing thermodynamic concepts of ecoexergy (Jorgensen and Svirezhev, 2004 ) and analogues to conventional measures of temperature, pressure and energy measures continues to be pursued.

\section{Educational Implications of NPT}

Many engineering problems in biochemical processing, environmental management and biology involve compartmental models, be they stirred tank reactors used to model environmental problem solutions or ecological niche models (also believed to be useful for environmental problem solutions). The conventional approach to understanding compartment models takes a homogeneous view of compartments. In other words, everything in a compartment has identical attributes as defined by property averages. 
The NPT approach first enlightened a group of faculty in engineering and ecology to the multiple scales at work in ecological compartment models. Other faculties across campus became stimulated by the multiple scale transport issue and have begun to cooperate with some in our research group to model genetics problems and model stochastic transport in biochemical networks. A growing group of graduate students are using NPT to understand mineral transport dynamics in streams (Small et al 2008).

A group of 8 honors students majoring in mathematics were instrumental in extending the NPT concept each suggested that their 'minds eye' vision of what happens in a constituent flowing network is enhanced by working with NEA enhanced by NPT. They were somewhat amazed that a compartment in apparent equilibrium on one level was never the same on a smaller scale. The concept of contaminant propagation through a compartmental system became stimulating to the group. The concept of individual passports or individual histories shows how individual particles can accumulate particular histories that may accelerate potency of that particle to infect or poison other particles.

From the growing interest among faculty and students, we are convinced that the NPT approach offers interesting and exciting possibilities for research in areas centered on transport of energy and constituents through compartments. The value of NPT from a pedagogical viewpoint is becoming apparent. Seeing the 'light come on' in the eyes of students of multiple disciplines is stimulating.

\section{Summary and salient implications}

NEA is a continuous, steady-state, input-output analyses based on conserved currency (e.g., energy, mass) movement through compartments (described by states), each with input-output environs that are connected. NPT discretizes the transported currency in the NEA model into "particles" or quanta that may acquire various designated history as the particle moves through the system prior to dissipation or exit. NPT offers avenues and suggests strategies for modeling dynamic and structural changes. NPT does not confer any Agency or life force in itself and does not suggest at this time any inherent structural change relations.

- NPT outputs related to contact history of particles in compartments seems to parallel NEA storage and throughflow analysis for compartments at low indirect effects and cycling index. At higher indirect effects and cycling, the correlation breaks perhaps due to increased diversity in compartmental types and turnover times in more complex systems.

- Particle movement is a type of internal time, enabling future thermodynamic analyses. NPT creates an inherent system memory and thus history development. Work to date has assumed uniform effect of all compartments and uniform external input effects. There is no reason to assume that all 
compartments should be equally weighted in terms of particle interactions. Weighting factors related to exergy or emergy may be useful. As a means of communication with the environment, particles also may bring history into the system from the environment. Perhaps this could form the basis for a strategy to increase the coupling of the modeled system with the environment. communication could occur in other ways with the environment.

- NEA analysis and current implementations of NPT do not allow for structural changes; however, NPT offers avenues for modeling structural change based on a 'demand function' defined using the attributes of particles passing through the system.

- NPT enables researchers and students alike to have a more realistic view of compartment dynamics in ecological and, by extension, other similar compartmental models found in bioprocessing and environmental domains.

\section{Acknowledgments}

The Research Experiences for Undergraduates (REU) program of NSF, administered under the Mathematics Department at The University of Georgia, contributed much to this effort. The organizers of the University of Sienna, Brainstorm at Pacina, Italy are thanked for enabling an intellectual climate that stimulated much discussion underlying ideas expressed in this paper. Thanks also to the Georgia Agricultural Experiment Station and to the University of Georgia Faculty of Engineering for financial support of this work. 


\section{References}

Barkmann, J., B. Breckling, T. Potthast and J. Badura. 1998. Introduction: Philosophical aspects of goal functions. IN Eco Targets, Goal Functions and Orientors (F. Muller and M. Leupelt, Eds). Springer-Verlag, Berlin, Germany.

Barber, M.C., Patten, B.C. and Finn, J.T. 1979. Review and evaluation of input-output flow analysis for ecological applications. In: Matis, J.H., Patten, B.C., and White, G.C. (Editors), Compartmental Analysis of Ecosystem Models. International Co-operative Publishing House, Fairland, MD.

Bass, B. 1998. Applying thermodynamic orientors: Goal functions of the Holling figure-eight model. IN Eco Targets, Goal Functions and Orientors (F. Muller and M. Leupelt, Eds). SpringerVerlag, Berlin, Germany.

Bossel H. 1992. Real-structure process description as the basis of understanding ecosystems and their development. Ecol. Modeling 63: 261-276.;

Fath, B.D. and Patten, B.C. 1999. Review of the foundations of network environ analysis. Ecosystems, 2:167-179.

Fath B.D., Jørgensen S.E., Patten B.C., and Straškraba M. 2004. Ecosystem growth and development. Biosystems. 77, 213-228.

Fath B.D., Patten B.C., and Choi J.S. 2001. Complementarity of ecological goal functions. J. Theoretical Biology. 208(4), 493-506.

Gillespie D.T., 1977. Exact stochastic simulation of coupled chemical reactions. Journal of Physical Chemistry. 81:2340-2361.

Gillespie D.T., 1992. A rigorous derivation of the chemical master equation. Physica A. 188:404-425.

Gillespie D.T., 2000. The chemical Langevin equation. Journal of Chemical Physics. 113:297306.

Jørgensen S.E. and Fath B.D. 2004. Application of Thermodynamic principles in ecology. Ecological Complexity. 1(4), 267-280.

Fath B.D. and Borrett S.R. 2006. A Matlab® Function for Network Environ Analysis.

Environmental Modelling and Software 21, 375-405.

Finn, J.T. 1976. Measures of ecosystem structure and function derived from analysis of flow. J. of Theor. Biol. 56:363-380.

Higashi M. and Patten, B.C. 1989. Dominance of indirect causality in ecosystems. Am. Nat. 133:288-302.

Jorgensen, S.E. and R. Ulanowicz. 2008. Network calculations and ascendency based on ecoexergy. Personal communication. 
Jorgensen, S.E. 2008. Evolutionary essays: A thermodynamic interpretation of the evolution. Elsevier, Amsterdam, Netherlands.

Jorgensen, S.E. and G. Bendoricchio. 2001. Fundamentals of Ecological Modeling, $3^{\text {rd }}$ Ed., Elsevier, Amsterdam, Netherlands.

Jorgensen, S.E. and S. N. Nielsen. 1998. Thermodynamic orientors: A review of goal functions and ecosystem indicators. IN Eco Targets, Goal Functions and Orientors (F. Muller and M. Leupelt, Eds). Springer-Verlag, Berlin, Germany.

Jorgensen, S. E. and Y.M. Svirezhev. 2004. Towards a thermodynamic theory for ecological systems. Elsevier Ltd. Amsterdam, The Netherlands.

Haven, D.S. and R. Morales-Alamo. 1966. Aspects of biodeposition by oysters and other invertebrate filter feeders. Limnology and Oceanography 11(3):487-498. Kazanci, C. 2007. EcoNet: new software for ecological modeling, simulation and network analysis. Ecological Modeling 208(1): 3-8.

Kazanci, C. and E.W. Tollner. 2008. Particle tracking: an integrated approach for solving ecological network models. J. Math. Biology (In Prep.).

Matis, J.H., Patten, B.C., White, G.C. (eds.), 1979. Compartmental Analysis of Ecosystem Models. International Co-operative Publishing House. Fairland, Maryland. USA. 368 p.

McLeod, S. and S.W. Running. 1988. Comparing site quality indices and productivity of ponderosa pine stands in western Montana. Canadian Journal of Forest Research 18: 346-352.

Patten, B.M. 1978. Systems approach to the concept of environment. Ohio Journal of Science 78: 206-222.

Patten, B.C. 1981. Environs: the super niches of ecosystems. American Zoologist 21: 845-852.1

Patten, B.C. and Auble, G.T. 1981. System theory of the ecological niche. Am. Nat. 117:893921.

Patten, B.C. 1982. Environs: relativistic elementary particles for ecology. American Naturalist 119: $179-219$.

Patten, B.C. 1998. Network orientors: Steps toward a cosmography of ecosystems: Orientors for directional development, self organization and autoevolution. IN Eco targets, goal functions and orientors, Pages 137-160, Ed. by F. Muller and M. Leupelt, Springer, Berlin, Germany.

Ratzsch, D. 1986. Philosophy of science. Intervarsity Press, Downers Grove, IL. 
Schramski, J.R. 2006. Distributed Control in the Environ Networks of a Seven Compartment Model of Nitrogen Flow in the Neuse River Estuary, North Carolina, USA. Ph.D. Dissertation, University of Georgia, Athens, GA.

Small, G.E., Helton, A.M., Kazanci, C. 2008. Can consumer regulation control nutrient spiraling in streams? JNABS. Submitted.

Tollner, E.W. and C. Kazanci. 2007. Defining an ecological thermodynamics using discrete simulation approaches, Ecological Modelling 228(1): 68-79.

Tollner, E.W., C. Kazanci, J. Schramski and B.C. Patten. 2008. Control System Approaches to Ecological Systems Analysis: Invariants and Frequency Response, Ecological Engineering (In Preparation).

Ulanowicz, R.E. 2000. Growth and Development: Ecosystems Phenomenology. iUniverse, Lincoln, NE.

Ulanowicz, R.E. 1998. Network orientors: Theoretical and philosophical considerations why ecosystems may exhibit a propensity to increase in ascendency. IN Eco Targets, Goal Functions and Orientors (F. Muller and M. Leupelt, Eds). Springer-Verlag, Berlin, Germany.

Webster, J.R., Waide, J.B., and Patten, B.C. 1975. In F.G.Howell, J.B. Gentry, and M.H. Smith eds. Mineral Cycling in Southeastern Ecosystems. ERDA Symposium Series Conf-740513, Springfield, Virginia.

Whitehead, A.N. 1933. Adventures of ideas. McMillan Publishing, New York, NY.

Zemansky, M.W. and R.H. Dittman. 1997. Heat and thermodynamics ( $7^{\text {th }}$ Ed.). McGraw-Hill Publishing Co., New York, NY. 


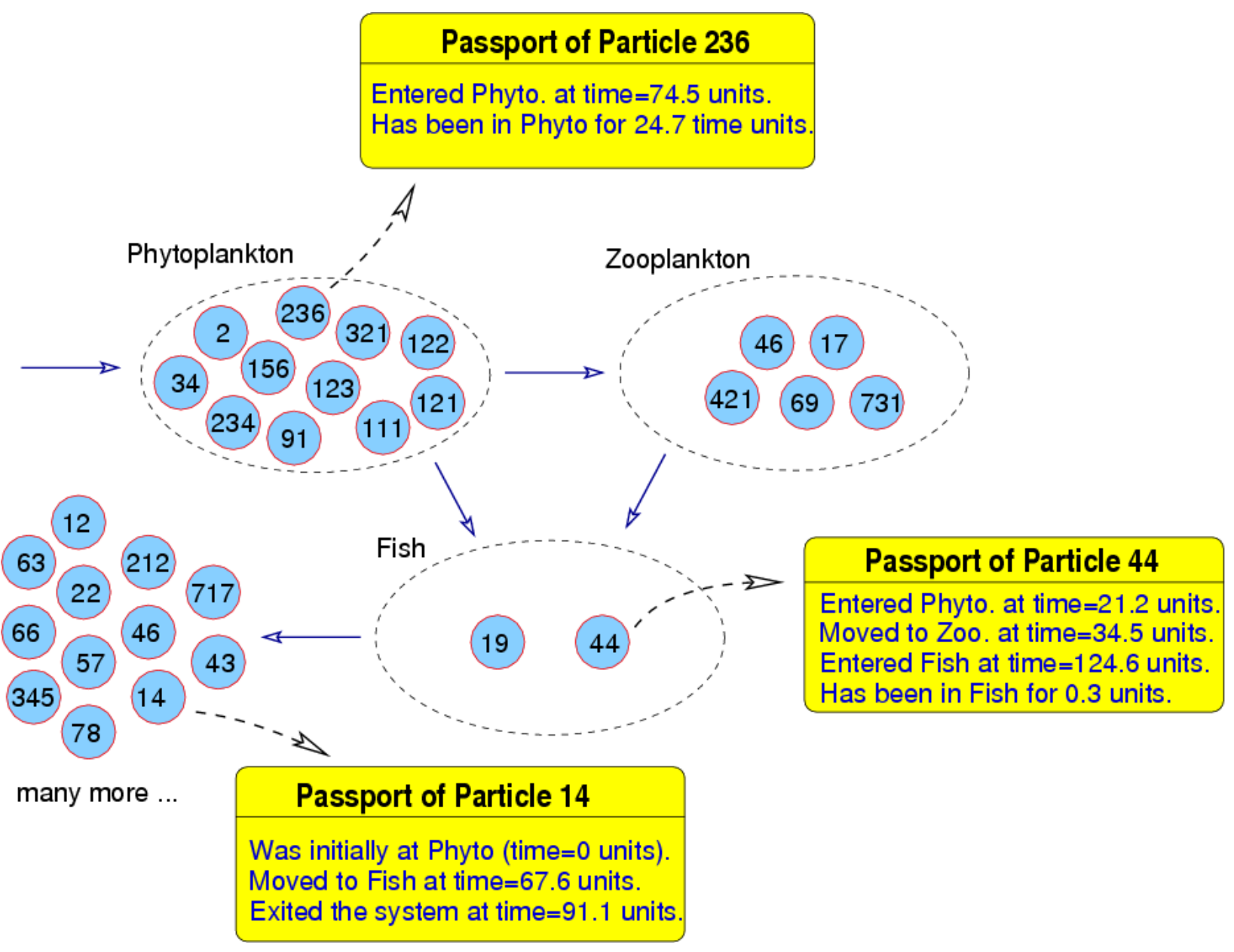

Figure 1. Hypothetical model depicting labeled discretized particles and their transport via NPT. 


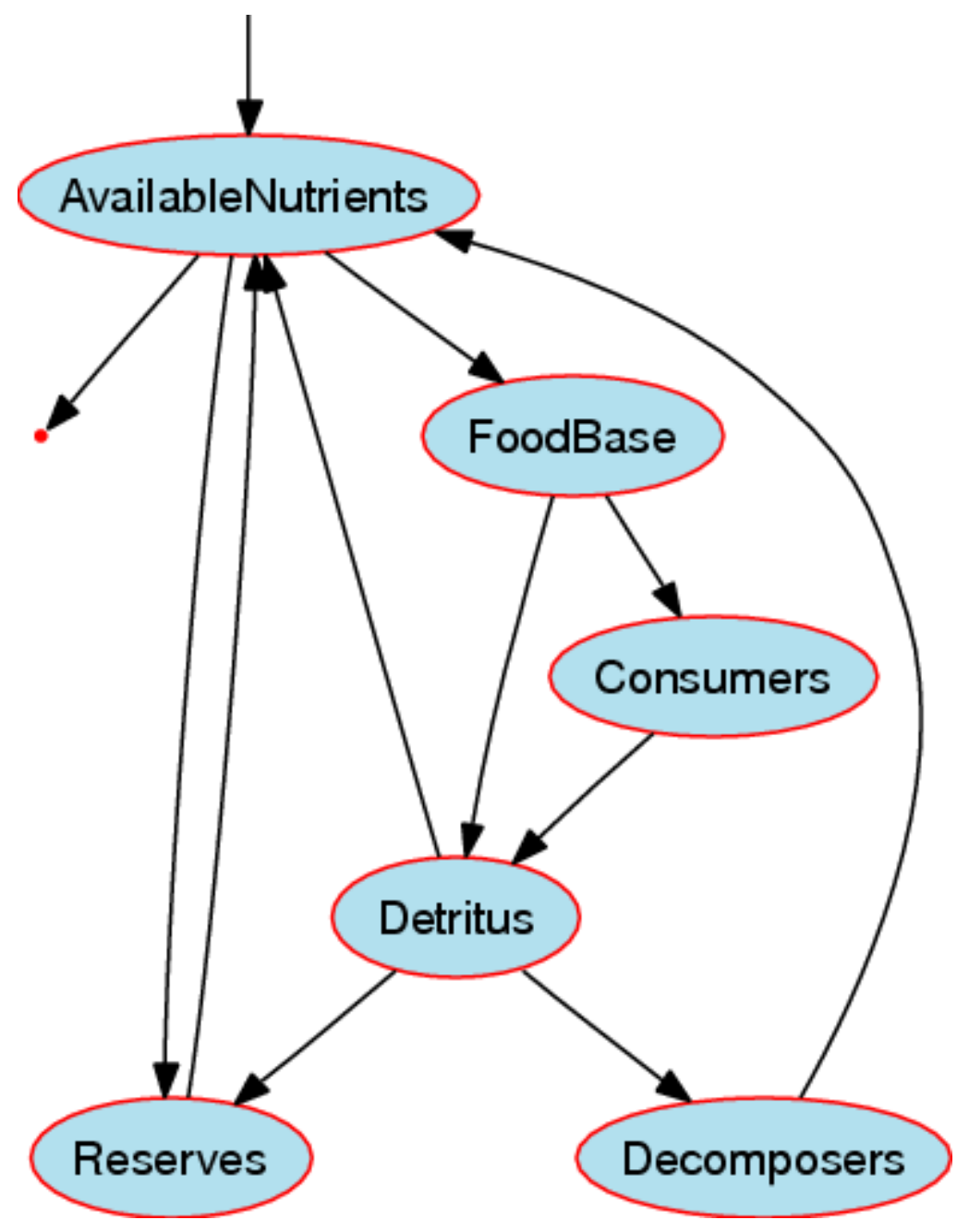

Figure 2a. EcoNet graphical output of mineral flows in a generic temperate forest ecosystem (Webster et al, 1975). 


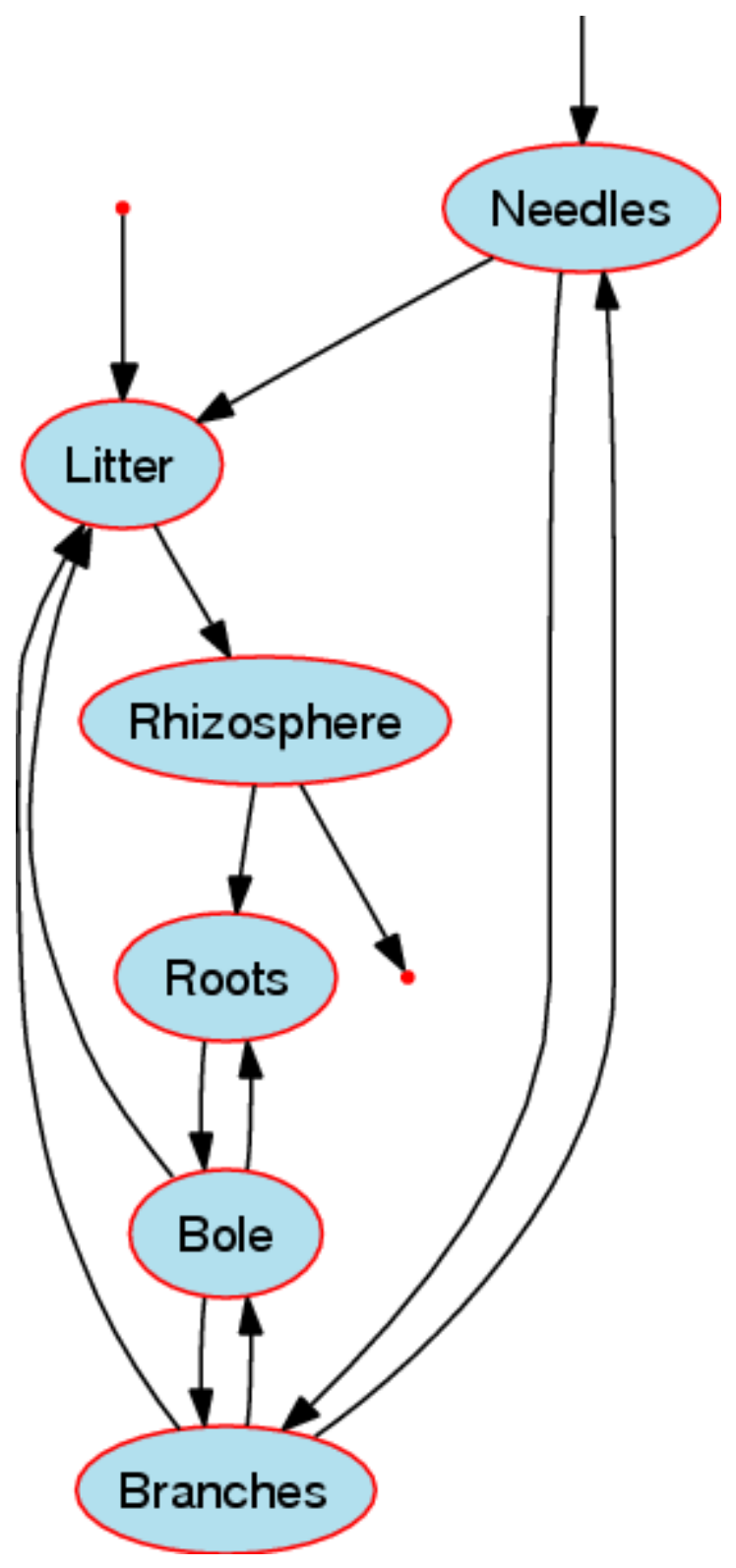

Figure 2b. EcoNet graphical output of energy flows in a nitrogen model, USA (McLeod and Running, 1988). 


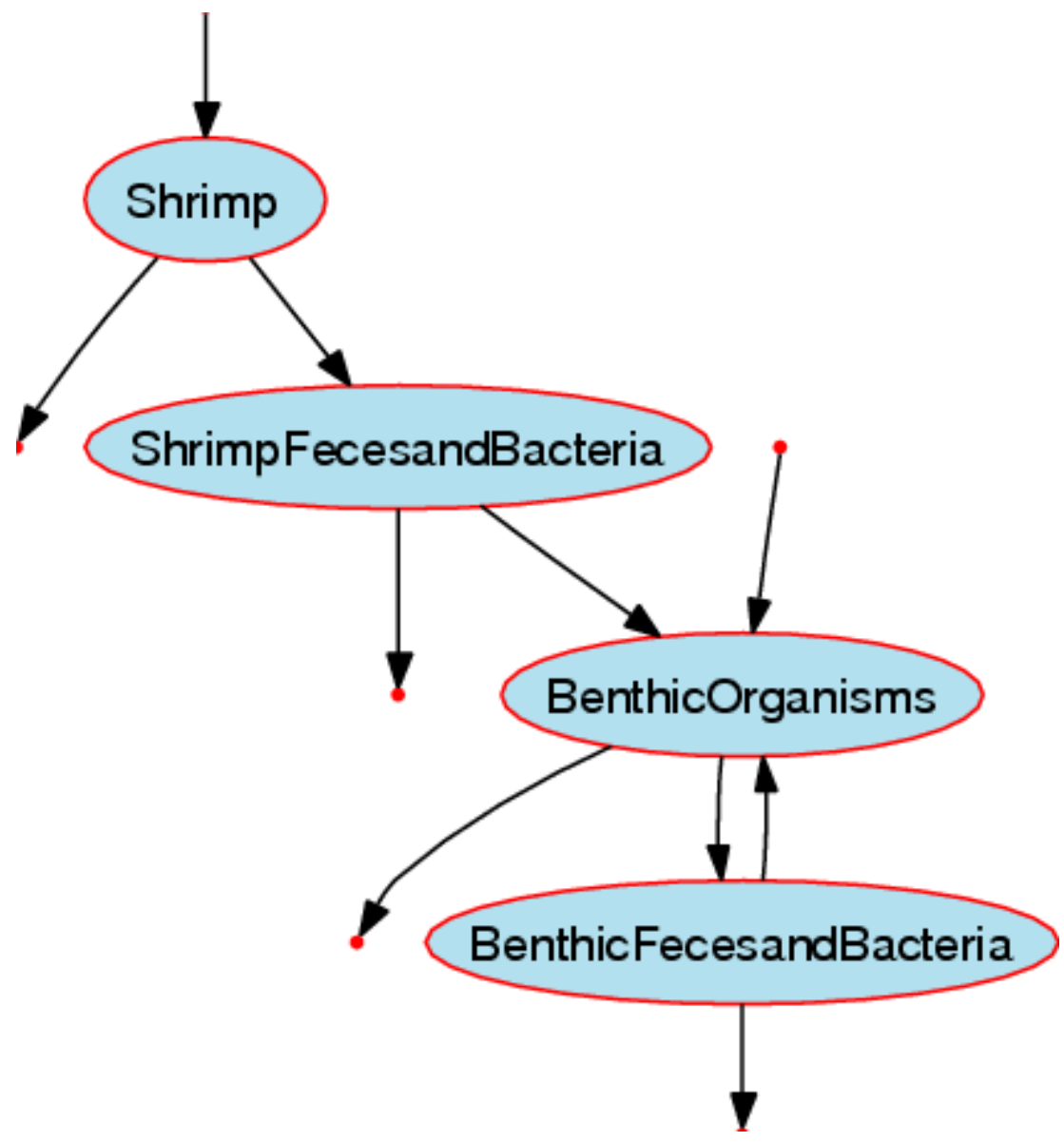

Figure 2c. EcoNet graphical output of energy flows in Coprophagic web, Chesapeake Oyster community, Virginia, USA (Haven D.S. and Morales-Alamo,1966) 
Number of particles
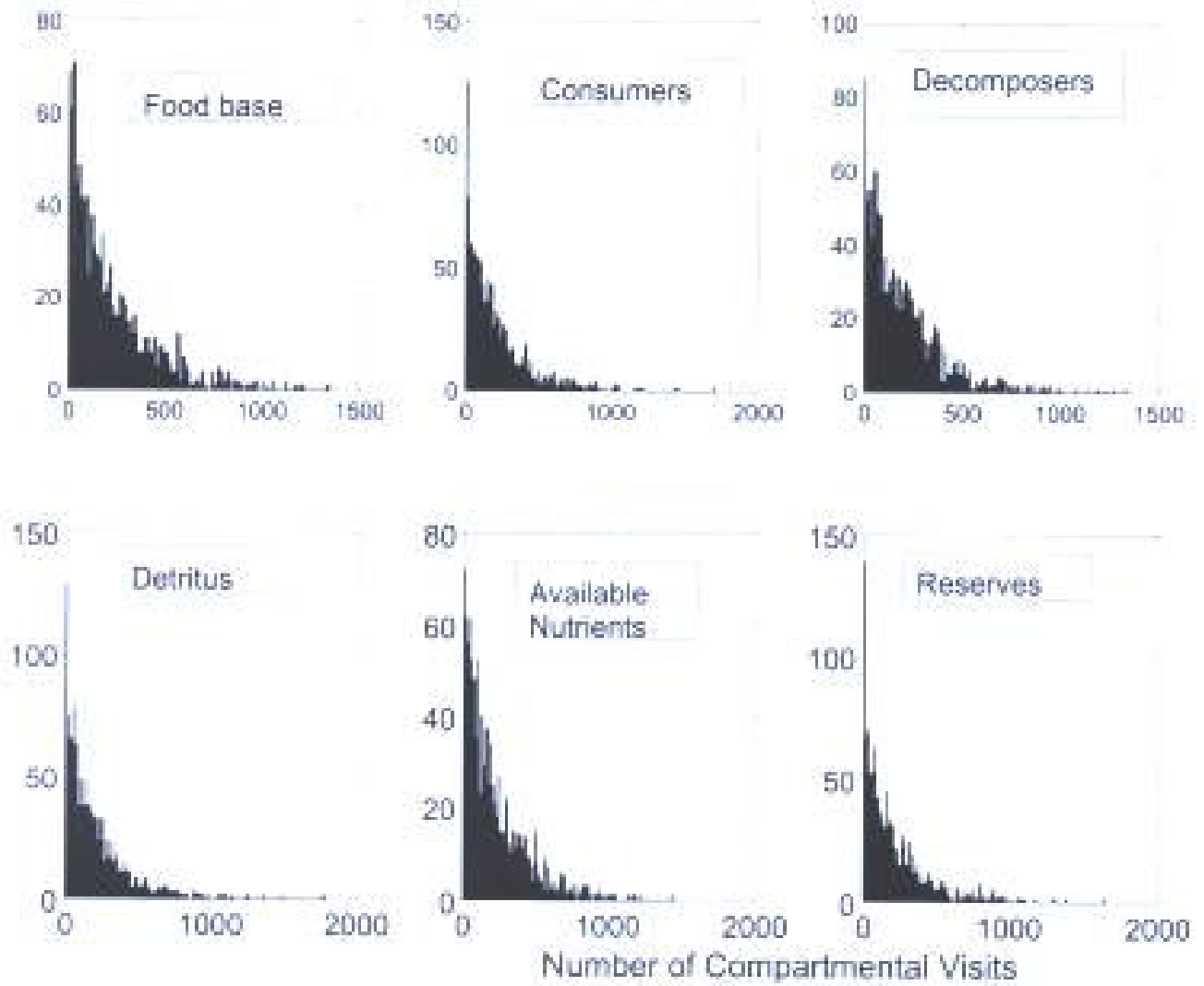

Figure 3a. Histograms of particle visits at steady state by compartments in the Webster et al (1975) tropical forest model.

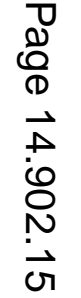


Number of particles
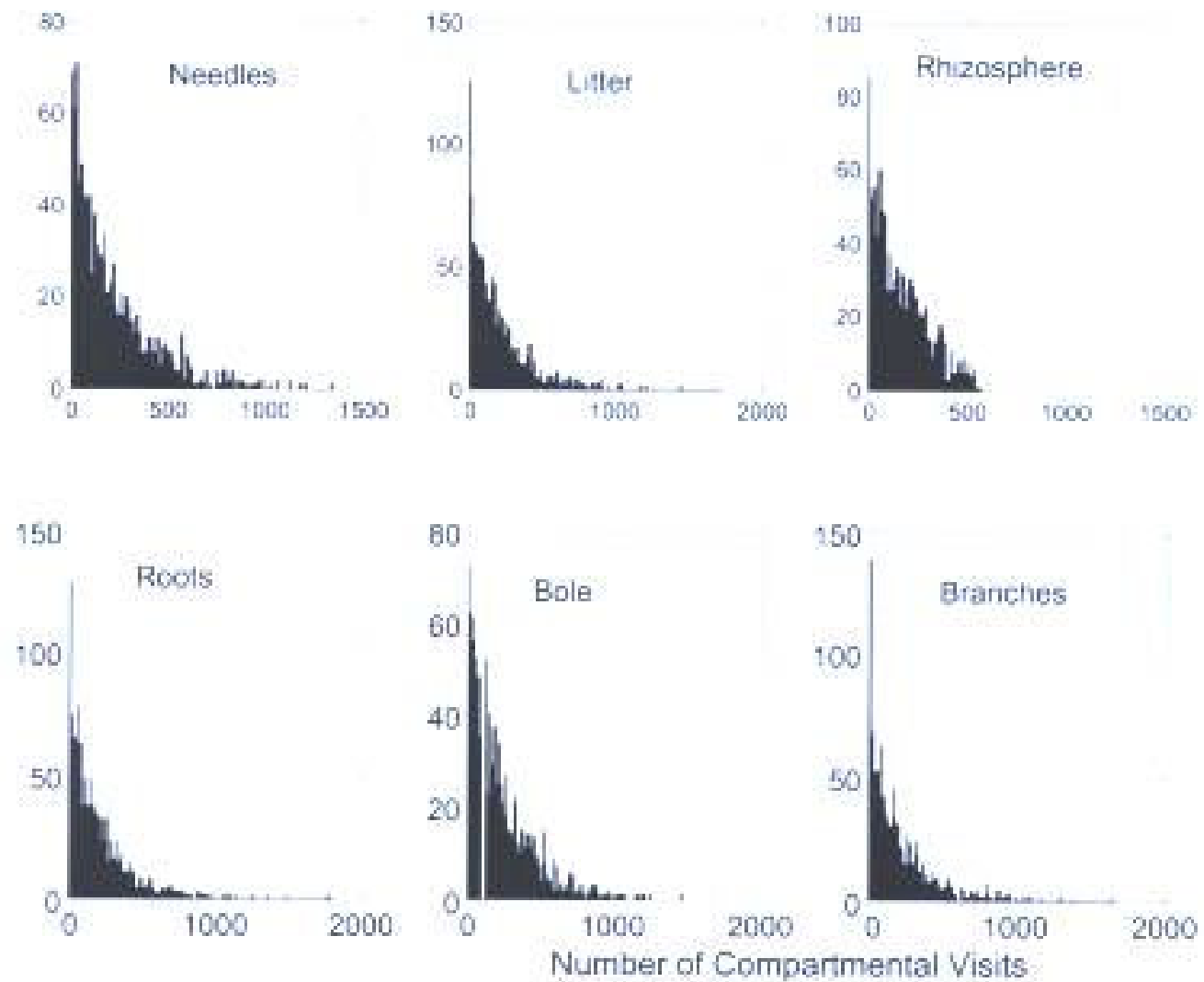

Figure 3b. Histograms of particle visits at steady state by compartments in the McLeod and Running (1988) forest model.

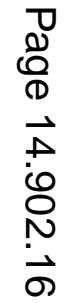




\section{Number of Particles}
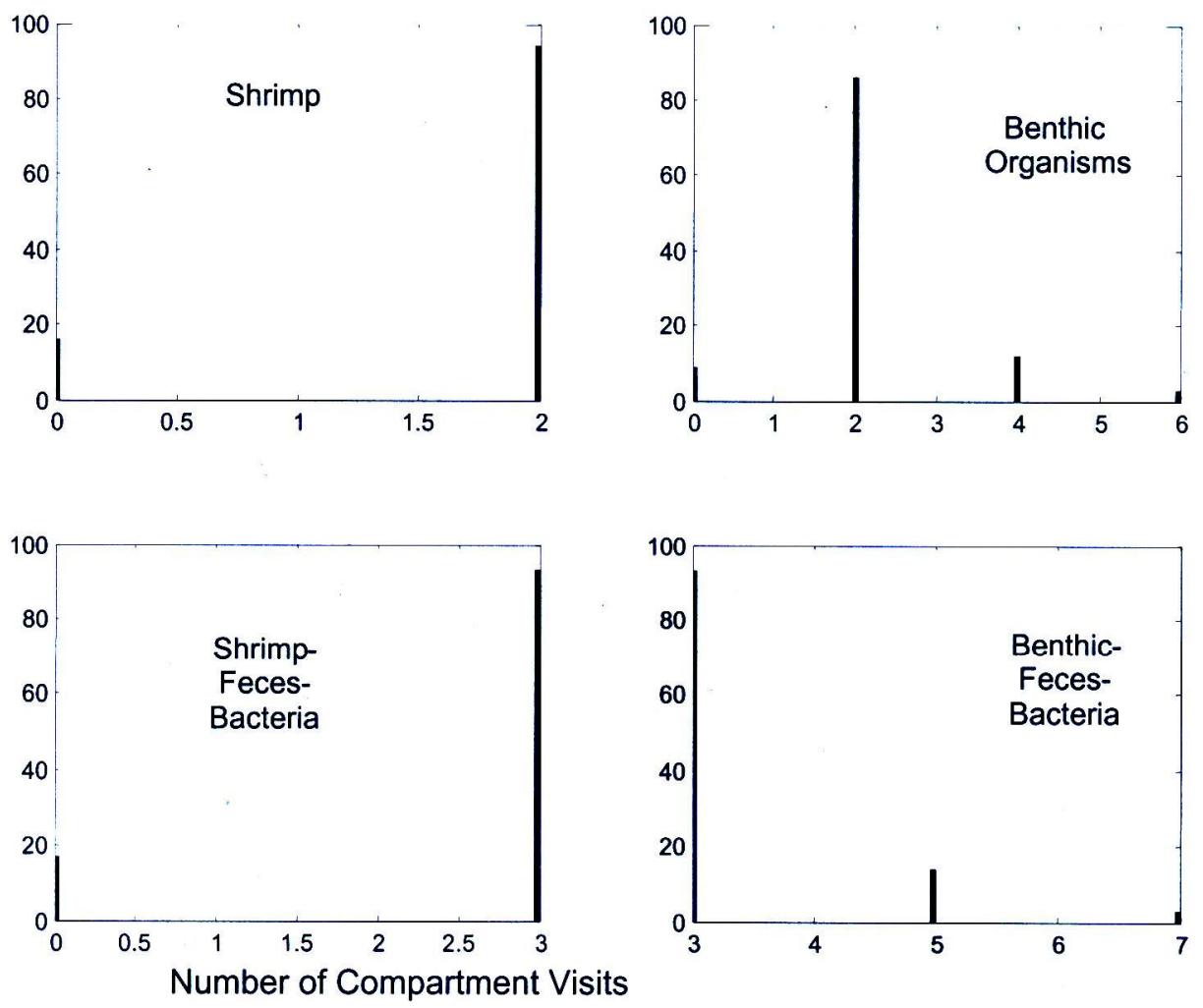

Figure 3c. Histograms of particle visits at steady state by compartments in the Haven, D.S. and R. Morales-Alamo (1966) Marine model. 
NEA storage

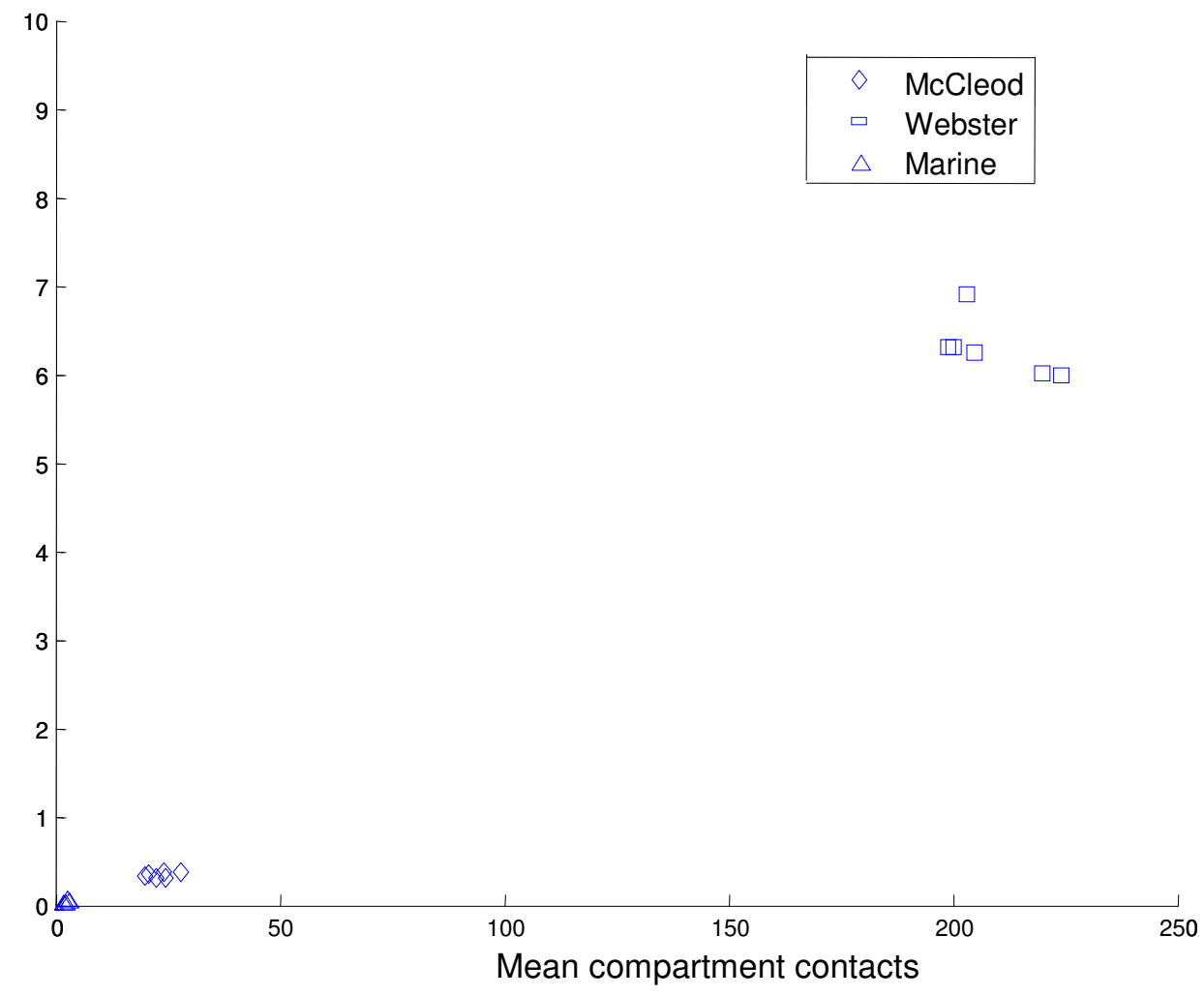

Figure 4a. NEA Storage per unit time versus average number of contacts of particles residing in that compartment (at steady state, average over time) for the indicated model. 
NEA

\section{Throughflow}

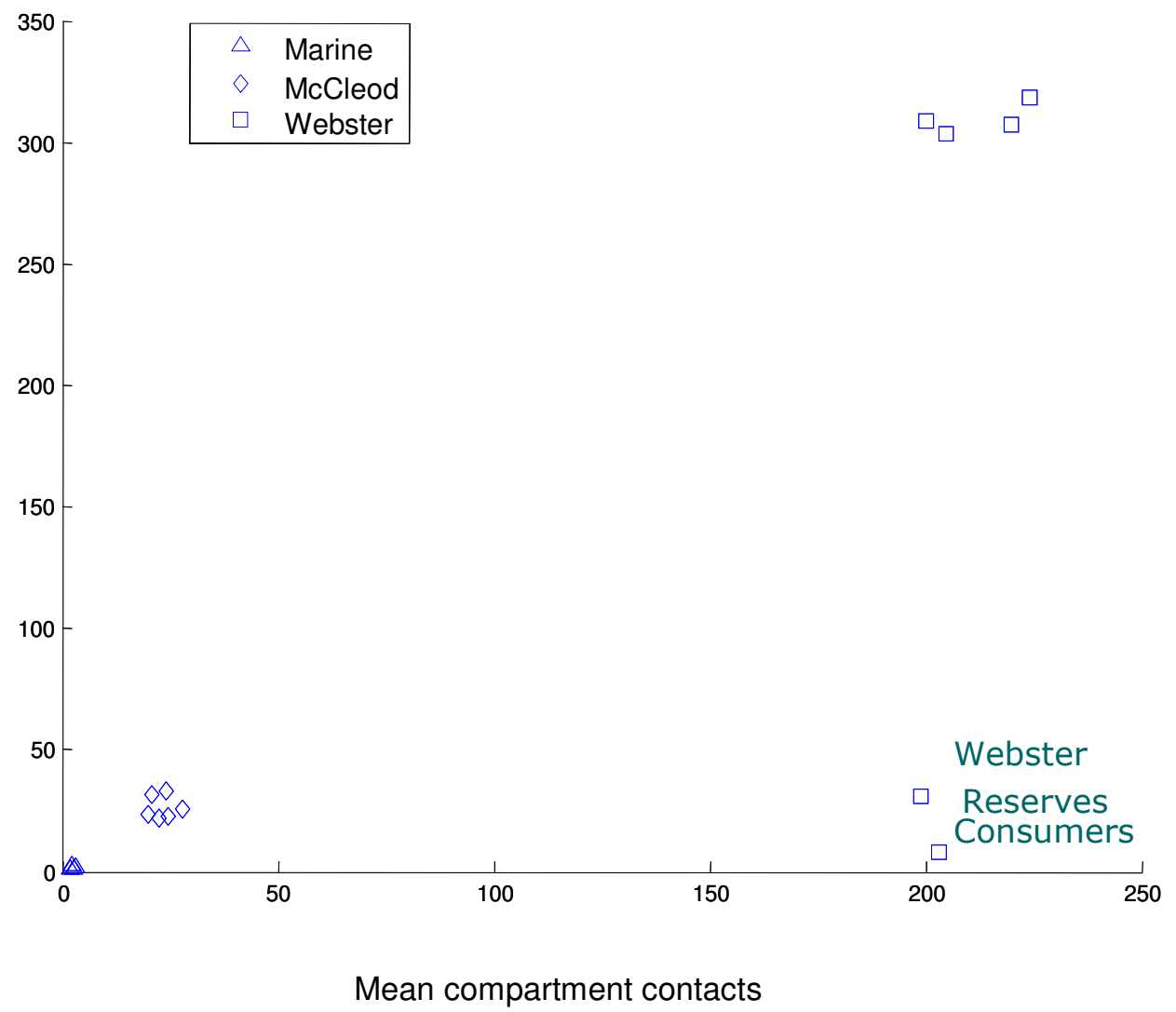

Figure 4b . NEA Throughflow versus average number of contacts of particles residing in that compartment (at steady state, average over time) for the indicated model. 
NEA Storage

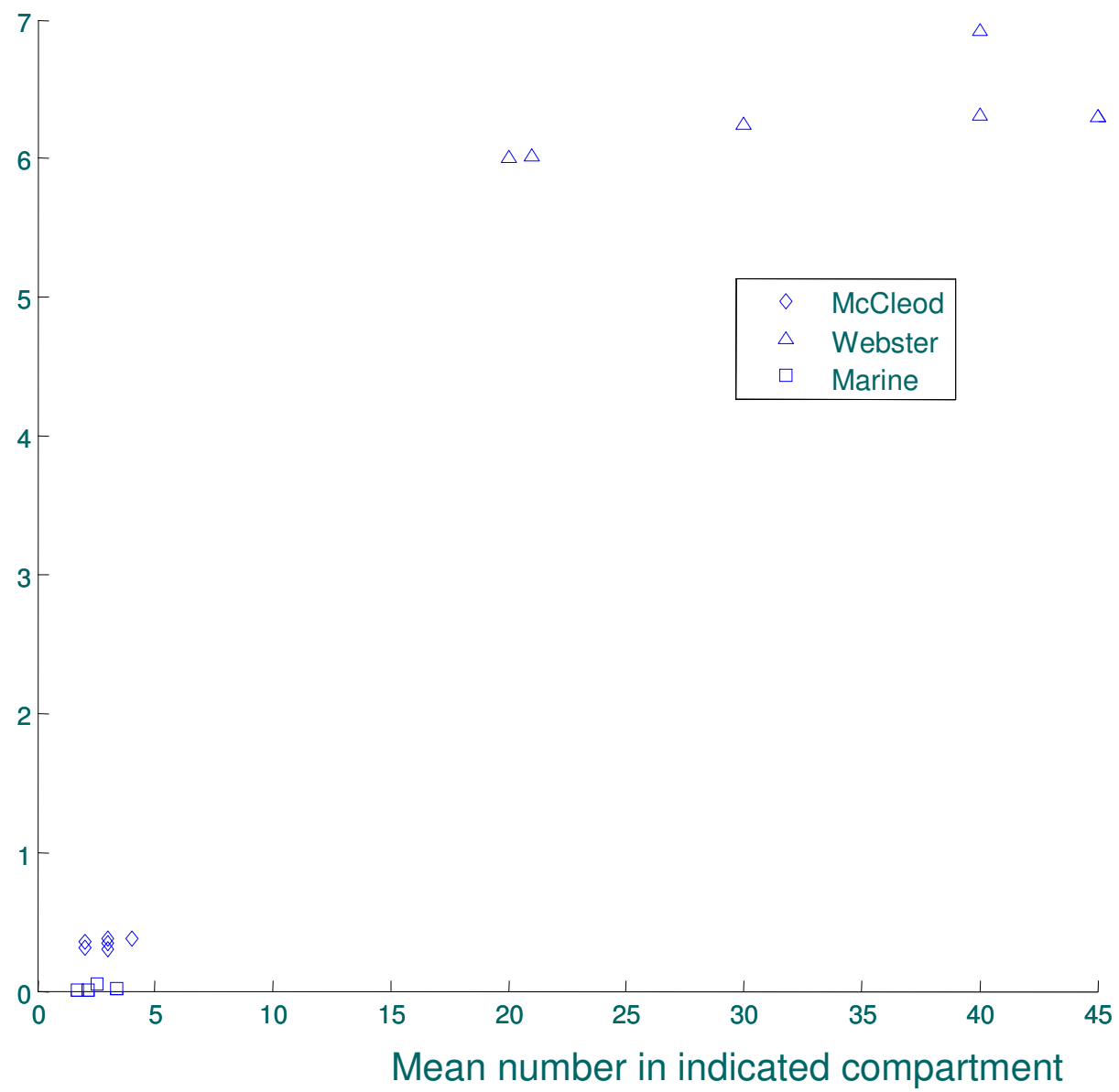

Figure 5a. NEA Storage versus average number of particles in the given compartment at steady state for the indicated model. 


\section{NEA Throughflow}

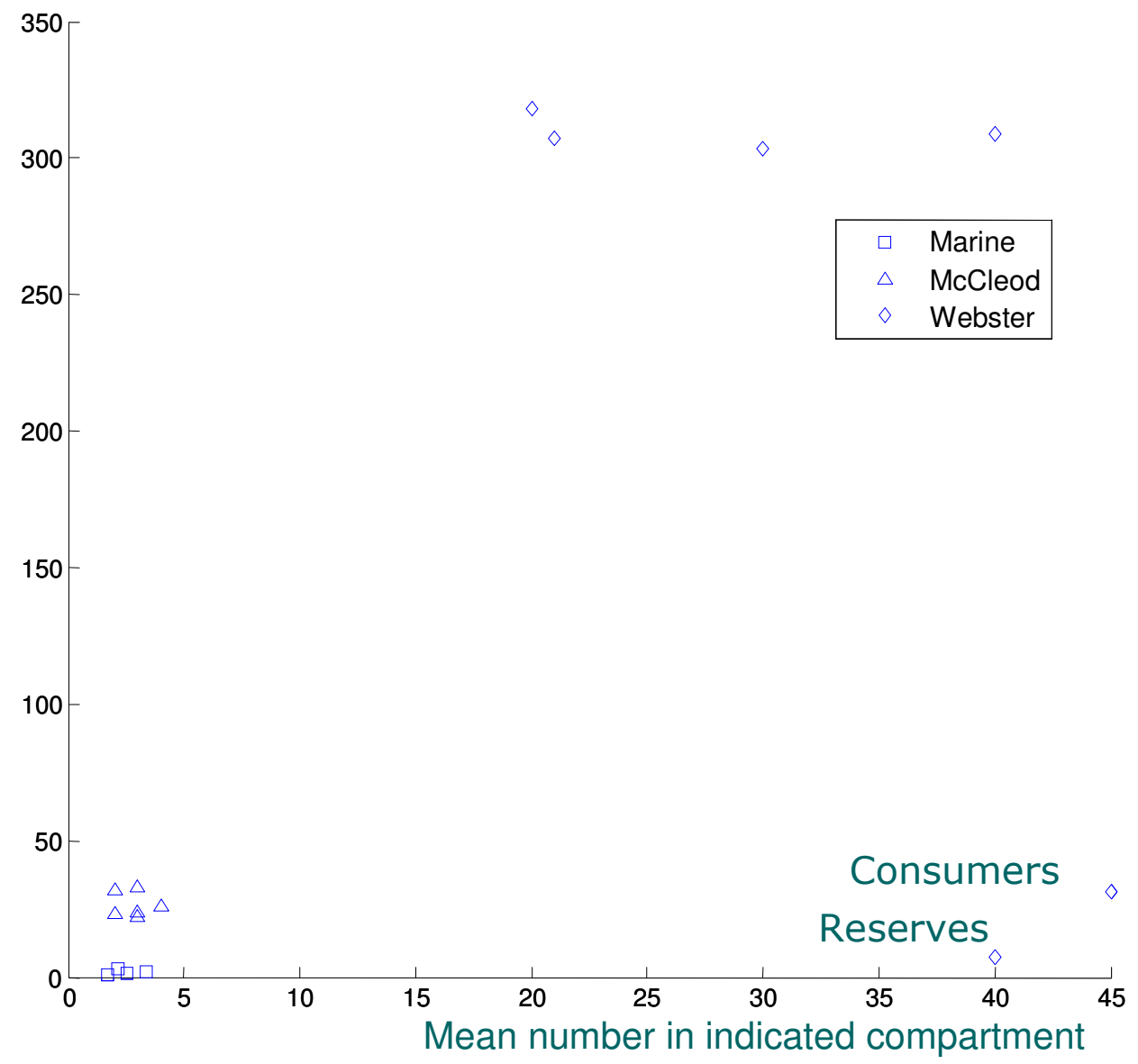

Figure 5b. NEA throughflow versus average number of particles in the given compartment at steady state for the indicated model. 
Table 1a. NEA compartment storage (kg/Ha), throughflow (kg/Ha-yr), and NPT mean, and mean particle numbers for Webster et al. (1975) Tropical Forest model of mineral nitrogen flow. Finn Cycling Index $=0.97$. Indirect to Direct Effects ratio $=211$.

\begin{tabular}{|c|c|c|c|}
\hline Compartment & $\begin{array}{l}\text { NPT } \\
\text { Mean compartmental } \\
\text { visits and (content } \\
\text { number) }\end{array}$ & $\begin{array}{l}\text { NEA } \\
\text { storage }\end{array}$ & NEA throughflow \\
\hline Food base & $\begin{array}{l}220 \\
(21)\end{array}$ & 6.01 & 307 \\
\hline Consumers & $\begin{array}{l}199 \\
(45)\end{array}$ & 6.30 & 31.1 \\
\hline Decomposers & $\begin{array}{l}205 \\
(30)\end{array}$ & 6.24 & 303 \\
\hline Detritus & $\begin{array}{l}200 \\
(10)\end{array}$ & 6.31 & 309 \\
\hline $\begin{array}{l}\text { Available } \\
\text { Nutrients }\end{array}$ & $\begin{array}{l}224 \\
(20)\end{array}$ & 6.00 & 318 \\
\hline Reserves & $\begin{array}{l}203 \\
(40)\end{array}$ & 6.91 & 7.60 \\
\hline
\end{tabular}


Table 1b. NEA compartment storage (kg N/Ha), throughflow (kg N/Ha-yr), and NPT mean, and mean particle content numbers for the McLeod and Running (1988) forest model. Finn Cycling Index $=0.79$. Indirect to Direct Effects ratio $=25.7$.

\begin{tabular}{|l|l|l|l|}
\hline Compartment & $\begin{array}{l}\text { Particle Tracking } \\
\text { Mean } \\
\text { compartmental } \\
\text { visits and } \\
\text { (content number) }\end{array}$ & NEA storage & NEA through-flow \\
\hline Needles & $\begin{array}{l}27.8 \\
(4)\end{array}$ & 0.376 & 25.68 \\
\hline Branches & $\begin{array}{l}24.01 \\
(3)\end{array}$ & 0.372 & 32.9 \\
\hline Bole & $\begin{array}{l}20.87 \\
(2)\end{array}$ & 0.354 & 31.9 \\
\hline Roots & 20.1 & 0.339 & 23.8 \\
\hline Ritter & 22.44 & & \\
\hline Rhizosphere & 24.38 & 0.315 & 23.0 \\
$(2)$ & & \\
\hline
\end{tabular}


Table 1c. NEA compartment storage $\left(\mathrm{kcal} / \mathrm{M}^{2}\right)$, throughflow (kcal/ $\left.\mathrm{M}^{2}-\mathrm{yr}\right)$, and NPT mean, and particle content numbers for the Haven and Morales-Alamo (1966) model of energy flow. Finn Cycling Index $=0.12$. Indirect to Direct Effects ratio $=0.61$.

\begin{tabular}{|c|c|c|c|}
\hline Compartment & $\begin{array}{l}\text { Particle Tracking } \\
\text { Mean } \\
\text { compartmental } \\
\text { visits and (content } \\
\text { number) }\end{array}$ & NEA storage & NEA throughflow \\
\hline Shrimp & $\begin{array}{l}18 \\
(2)\end{array}$ & 0.0081 & \begin{tabular}{|l|l} 
\\
\end{tabular} \\
\hline Benthics & $\begin{array}{l}40 \\
(2)\end{array}$ & 0.009 & 2.96 \\
\hline $\begin{array}{l}\text { Shrimp, Feces, } \\
\text { Bacteria } \\
\text { complex }\end{array}$ & $\begin{array}{l}40 \\
\text { (3) }\end{array}$ & 0.05 & 1.17 \\
\hline $\begin{array}{l}\text { Benthic, Feces, } \\
\text { Bacteria } \\
\text { complex }\end{array}$ & $\begin{array}{l}10 \\
(3)\end{array}$ & 0.02 & 1.72 \\
\hline
\end{tabular}

